\title{
ПОЧЕМУ ИТАЛИЯ ПРОТИВ ГЛОБАЛЬНОГО ДОГОВОРА О МИГРАЦИИ?
}

\begin{abstract}
Аннотация. В статье рассмотрены причины отказа Италии от участия в глобальной инициативе ООН по регулированию миграџии. Автор анализирует влияние внутриполитической и общественной обстановки в стране на решение о неприсоединении к Глобальному догово́ру о миграции.
\end{abstract}

Ключевые слова: мигранты, Италия, Глобальный договор, регулирование мигращии, Европейский союз, Лига.

Одним из проявлений современных процессов глобализации, наряду с активным международным движением капитала, товаров, услуг стала массовая миграция населения. Уже к середине XX столетия возросло количество не только стран - экспортёров мигрантов, но изменились масштаб и направления миграционных потоков. Миграционные процессы затронули в той или иной степени все континенты, в том числе и европейский ${ }^{1}$.

По оценкам ООН, свыше 258 млн человек ${ }^{2}$ живут за пределами страны, в которой они родились, а в будущем эта цифра увеличится из-за быстрого роста населения и неравномерного развития экономики в различных странах мира, что приводит к социальному неравенству, из-за демографических проблем и изменения климата.

Эффективное управление миграционными потоками является на данный момент одной из важнейших задач для стран - членов Европейского союза, ЕС как объединения и, наконец, в отношениях ЕС с другими государствами. Миграционные процессы в Европе представляют собой новый вызов, как для национальных государств, так и для Европейского союза в целом.

Катализаторами массового исхода беженцев и мигрантов из «проблемных» государств «арабского мира» в развитые страны Европы и, прежде всего, в Италию стали события «арабской весны», а именно дестабилизация обстановки в регионе Северной Африки и Ближнего Востока, обострение существующих межконфессиональных и этнокультурных противоречий и, в целом, нестабильная ситуация в районе Сахеля. В силу своего уникального географического положения - большая часть Италии расположена в Средиземном море, а отдельные её острова почти примыкают к берегам Ливии и Туниса - для выходцев с африканского побережья Италия стала желаемым местом конечного назначения или, как минимум, удобным перевалочным пунктом на пути в другие части $\mathrm{EC}^{3}$.

(С Шогунц Анна Вардановна - аспирант ИЕ РАН. Адрес: 125009, Россия, Москва, ул. Моховая, д. 11, стр. 3. Email: annashoghunts@mail.ru.

DOI: http://dx.doi.org/10.15211/vestnikieran2201999105

${ }^{1}$ OECD, International Migration Outlook 2014. OECD Publishing. Paris. 2014. P. 19.

2 More Than 150 Nations Adopt UN Migration Pact. Voice of America. 2018. URL: https://www.voanews.com/a/unmigration-pact/4693902.html.

${ }^{3}$ Шогунц А.В. Иммиграционный кризис в Италии в контексте событий «арабского пробуждения». Секция «Региональные проблемы международных отношений: Запад». Международная научная конференция студентов, 
Произошедшая в 1970-1980-е гг. трансформация Италии из страны эмиграции в страну притяжения мигрантов была воспринята болезненно итальянским обществом. Италия избегала любого признания того, что прибытие людей из разных стран неизбежно приводит к структурным социальным изменениям. Вместо этого десятилетиями итальянская политическая элита рассматривала иммиграцию как «критическую ситуацию» ${ }^{1}$, что препятствовало адекватной оценке изменений общественно-политического пространства государства. Тем не менее, к началу 1990-х гг. (при общем «запаздывании» и противоречивости предпринимаемых государством мер в области регулирования миграционных потоков) соответствующая проблематика заняла лидирующее место в общественных дискуссиях. События «арабской весны», ставшие точкой отсчёта миграционного кризиса в Европе, вынудили итальянское общество встать на путь усиленного поиска идентичности, с неизбежными для него конфликтами на почве разницы ценностей, традиций и культуры в целом.

Дискуссии о самоопределении в итальянском обществе разворачивались в двух плоскостях: 1) внутринациональной, а именно - как остаться итальянцем в условиях притока мигрантов, и 2) европейской, т.е. как остаться итальянцем в объединённой Европе. Невнимание властей к адаптации иммигрантов, проведение политики мультикультурализма (хоть и не провозглашённой официально), а также отсутствие стратегии регулирования миграционных процессов обернулись появлением в Италии «параллельных сообществ». Стремительный рост числа мигрантов породил проблему ксенофобии и расизма в итальянском обществе. Тема иммиграции оказалась сильно политизирована, что привело к широкому распространению стереотипного представления о мигрантах как об угрозе экономического, социального и культурного рода.

Волна мигрантов хлынула из Северной Африки через Средиземное море в Европу в начале 2011 г. после того, как в отдельных североафриканских странах начались народные волнения. В первую очередь, это коснулось Италии.

Географическое положение «южных ворот» в ЕС обусловило привлекательность Италии в качестве государства-транзита для выходцев с североафриканского побережья. Последние составляют вторую в количественном измерении когорту мигрантов. Наиболее многочисленной подгруппой являются тунисцы и эритрейцы, следом за ними идут представители других североафриканских стран. Начиная с 2011 г., политическая нестабильность в государствах Северной Африки существенно увеличила миграционную нагрузку на страны Южного Средиземноморья (особенно пострадали от наплыва иммигрантов итальянские острова Лампедуза, Сицилия и Сардиния). На современном этапе большинство беженцев и мигрантов прибывает в Италию из стран Северной и Центральной Африки, реже - из стран Ближнего Востока и стран Персидского залива 2 .

Согласно данным Международной организации по миграции, в период с января по сентябрь 2018 года в Италию прибыло 21,024 мигранта, что на 80\% меньше по сравнению с 105,409 зарегистрированными мигрантами за тот же период 2017 года (из них 98,091 человек - из Ливии) и на 84\% меньше, чем за аналогичный период 2016 года (132,043 человека) ${ }^{3}$.

По данным итальянского Министерства внутренних дел ${ }^{4}$, выходцы из Туниса представ-

аспирантов и молодых учёных «Ломоносов 2016». М., 2016.

${ }^{1}$ Италия в начале XXI века (сб. статей по итогам конференции). Отв. ред. А.В. Авилова, Ю.Д. Квашнин. М., ИМЭМО РАН, 2015. С. 64-72.

${ }^{2}$ Mixed Migration Flows in the Mediterranean and Beyond. Compilation of Available Data and Information. Reporting Period: 2015. International Organization for Migration. 2015. P. 18.

${ }^{3}$ Mixed Migration Flows in the Mediterranean. Compilation of Available Data and Information. International Organization for Migration (IOM). 2018. P. 13.

${ }^{4}$ Italian monthly arrivals. Italian Ministry of Interior. Department of civil liberties and immigration. 2018. P. 8. Научно-аналитический вестник ИЕ РАН, 2019, №2 
ляют собой бо́льшую часть прибывших в первые несколько месяцев 2018 г. (21\%), затем следуют мигранты из Эритреи (15\%), Судана (8\%), Пакистана (6\%), Ирака (6\%) и Нигерии (6\%) наравне с представителями других национальностей Африки и Южной Азии. Число прибытий мигрантов с территории Ливии сократилось на $87 \%$ по сравнению с тем же периодом прошлого года и составило около 64\% всех въехавших в Италию мигрантов. Оставшаяся часть мигрантов прибыла в Италию из Кот-д’Ивуара и Алжира (по 5\% от общего числа), Мали и Гвинеи (по 4\%), и других стран (20\%) ${ }^{1}$.

Больше всего мигрантов в августе 2018 г. высаживалось в портах Сицилии (Поцалло, Лампедуза, Катания, Мессина, Трапани) $)^{2}$. Большинство прибыло в течение месяца самостоятельно на небольших лодках, которые отходили от берегов Туниса и прибывали на Лампедузу или на западное побережье Сицилии, и парусных лодках, маршрут которых пролегал из Турции в Калабрию и Апулию. В сентябре 2018 г., по данным, приведённым МОМ, из Ливии было отмечено лишь 2 прибытия (5 человек зарегистрировано 18 сентября и 62 человека - 22 сентября) $)^{3}$.

Одним из важнейших аспектов миграционного кризиса в Италии стало неравномерное распределение мигрантов, которое часто находилось вне контроля центрального правительства, оставаясь на усмотрение глав регионов. В Италии более благоприятные условия труда и социальной интеграции для иностранных работников предоставляют северные и центральные области. Соответственно, расположенные там крупные города отличаются высокими показателями концентрации легальных иммигрантов. Одновре́менно широкое использование труда нелегальных мигрантов теневым сектором экономики в наибольшей степени развито на юге

На пути к поиску решения этих проблем руководство Италии с самого начала поддержало Европейскую повестку дня по миграции (2015 г.), особенно в части, касающейся распределения квот для расселения ищущих убежище в странах ЕС. Вместе с тем покинувший свой пост в марте 2018 г. премьер-министр Италии М. Ренци неоднократно заявлял, что миграционный кризис в Европе стал результатом спорных и контрпродуктивных политических решений Евросоюза в отношении Сирии и Ливии. Он также критиковал руководство ЕС за медлительность в принятии действенных мер по миграционной проблеме. Кроме того, по мнению Италии и других сторонников введения квот для ищущих убежище, Дублинский регламент безнадёжно устарел, а по вопросу охраны внешних границ ЕС Италия выступает за реформирование действующей системы пограничных сил ЕС на базе агентства Frontex ${ }^{5}$.

\section{Глобальный договор и реакция Италии}

На глобальном уровне одной из важнейших и относительно успешной можно назвать инициативу по осуществлению регулирования миграции, принявшей форму Глобального соглашения ООН по миграции. Идея Глобального договора зародилась после принятия ООН в 2016 г. Нью-Йоркской декларации по беженцам и мигрантам, активно лоббируемой США. Соглашение призвано упорядочить глобальную миграцию населения, управляя ею на международном уровне, что помогло бы избежать жертв и интегрировать иммигрантов в общество новых стран проживания.

\footnotetext{
${ }^{1}$ Mixed Migration Flows in the Mediterranean. Compilation of Available Data and Information. International Organization for Migration (IOM). 2018. P. 13.

${ }^{2}$ Italian monthly arrivals. Italian Ministry of Interior. Department of civil liberties and immigration. 2018. P. 6.

${ }_{4}^{3}$ Mixed Migration Flows in the Mediterranean. Compilation of Available Data and Information... 2018. P. 14.

${ }_{5}^{4}$ Italian monthly arrivals ... 2018. P. 5.

${ }^{5}$ ЕС перед вызовом миграционного кризиса. Позиции европейских стран. Под ред. Н.К. Арбатовой, А.М. Кокеева. М., ИМЭМО РАН, 2016. С. 29-33.
}

Научно-аналитический вестник ИЕ РАН, 2019, №2 
Первоначально было выделены два направления урегулирования глобальных миграций населения - переговоры по Глобальному договору о беженцах и переговоры по Глобальному договору о безопасной, упорядоченной и легальной миграции ${ }^{1}$, целью которого являлось облегчение миграционной нагрузки на страны приёма мигрантов посредством экономической адаптации мигрантов и предоставления им упрощённой процедуры переезда в Европу ${ }^{2}$.

И если Глобальный договор о беженцах Италия благополучно подписала, то в отношении Глобального договора о мигрантах не всё так однозначно. Итальянское правительство во главе с премьер-министром Джузеппе Конте вначале объявило о готовности подписать новые предложения ООН по глобальному управлению миграционными потоками, однако в последний момент отказалось от участия в конференции в Марокко в декабре 2018 г. и предоставило принять решение по этому вопросу парламенту страны. Стоит отметить, что и внутри страны против участия Италии в Глобальном договоре о миграции выступали большинство партий правящей коалиции, а некоторые итальянские политики назвали документ «сумасшедшим» ${ }^{3}$.

Кроме того, итальянские право-популистские партии ещё до принятия Договора критиковали его из-за отсутствия конкретных предложений по регулированию проблемы массовой миграции населения, в том числе за закрепление за принимающими странами необходимости гарантировать мигрантам «полную интеграцию в общество» и «бороться с дискриминацией и подготовить общество, изменив его отношение к иммигрантам» 4.

Осложнило ситуацию и то, что вынесение на суд государств Глобального догово́ра произошло в момент усиления популистских партий с анти-иммигрантской риторикой в Италии, к представителям которых относятся премьер-министр Италии Джузеппе Конте и министр внутренних дел Маттео Сальвини. Неудивительно, что позиция Италии в отношении Глобального догово́ра о миграции кардинально изменилась в процессе переговоров по его принятию, ведь запрос на ужесточение миграционной политики в Италии на данный момент выражен гораздо сильнее, чем идея либерализации миграционного режима, которую предлагает Глобальный догово́р.

В этой ситуации итальянские законодатели поддержали правительство, приняв 18 декабря 2019 г. окончательное решение о неприсоединении к Глобальному догово́ру о миграции ${ }^{5}$ особенно на фоне принятия в ноябре 2018 г. итальянским парламентом подавляющим большинством голосов нового жёсткого закона об иммиграции и безопасности DL 113/2018 ${ }^{6}$, основной целью которого является ограничение числа мигрантов, пытающихся остаться в Италии. В этих целях отменяется вид на жительство как способ гуманитарной защиты для мигрантов, которые не имели права на получения статуса беженцев (при этом продлён срок содержания мигрантов в репатриационных центрах для проверки их личности и гражданства). В рамках нового закона предусмотрено составление Италией списка «безопасных стран», в которых существуют демократические политические системы и в целом отсутствуют поли-

\footnotetext{
${ }^{1}$ Биссон Л.С. Миграция вновь нарушает единство Евросоюза. Европейский Союз: факты и комментарии. М., 2018. Вып. 94. С. 61.

Global Compact on Refugees. URL: https://refugeesmigrants.un.org/ru/refugees-compact.

${ }^{3}$ Global Compact расколол Европу. Столетие. 2018. URL: http://www.stoletie.ru/politika/global_compact_raskolol_ jevropu_986.htm.

${ }_{5}$ Там же.

5 TESTI ALLEGATI ALL'ORDINE DEL GIORNO della seduta n. 102 di Martedì 18 dicembre 2018. Parlamento Italiano. 2018.

http://www.camera.it/leg18/995?sezione=documenti\&tipoDoc=assemblea_allegato_odg\&idlegislatur $\mathrm{a}=18$ \&anno=2018\&mese $=12$ \&giorno $=18 /$

${ }^{6}$ Conversione in legge, con modificazioni, del decreto-legge 4 ottobre 2018, №113. Parlamento Italiano. 2018. URL: http://documenti.camera.it/leg18/pdl/pdf/leg.18.pdl.camera.1346_A.18PDL0037320.pdf.
}

Научно-аналитический вестник ИЕ РАН, 2019, №2 
тические преследования; выходцам из этих стран будет отказано в любых формах помощи со стороны государства ${ }^{1}$. Министр внутренних дел М. Сальвини высоко оценил предполагаемую эффективность принятого закона, который, по его мнению, «обеспечит порядок, установит правила, прозрачность и единообразие в системе приема мигрантов», станет преградой для экономических мигрантов и преступников ${ }^{2}$.

Следует отметить и отрицательное отношение большинства итальянцев (71\%) к мигрантам, выявленное в ходе опроса, проведённого американским исследовательским центром Пью весной 2018 г. в 27 странах $^{3}$. Результаты исследования показали, что респонденты выступают против проводимой ЕС политики приема мигрантов. Так, больше половины (56\%) опрошенных итальянцев считают, что необходимо сократить число принимаемых мигрантов, а 15\% опрошенных против принятия всех мигрантов без исключения.

Глобальный догово́р о миграции был всё же подписан на межправительственной конференции в Марракеше и утверждён 19 декабря 2018 г. на заседании Генеральной Ассамблеи ООН. К Договору о миграции не присоединились ряд государств, таких как США, Италия, Австрия, Швейцария, Чехия, Венгрия, Словакия, Польша, Болгария, Хорватия, Израиль, Австралия.

Именно защитой итальянцев лидер право-популистской Лиги М. Сальвини объяснил нежелание Италии пойти на компромисс в отношении правил приема мигрантов, устанавливаемых Глобальным договором. В то же время министр иностранных дел Италии Энцо Моаверо Миланези в очередной раз предложил ЕС организовать финансовую помощь странам Африки, чтобы попытаться сдержать антиимиграционные настроения населения ${ }^{4}$.

\section{Выводы}

Миграционный кризис повлиял на внутриполитическую обстановку, прибавив сторонников право-популистским партиям и выдвинув на передний план общественных дискуссий тему безопасности. В этих условиях Италия закономерно отошла от идеалов мультикультурализма, и современная интеграционная политика страны имеет тенденцию к ужесточению.

На фоне текущих миграционных процессов в Италии и нежелания правящей популистской коалиции терять общественную поддержку проводимой итальянским кабинетом запретительной миграционной политики правительство отвергло Глобальный догово́р о миграции. В попытке урегулировать сложившуюся ситуацию правительством был инициирован новый закон, ужесточающий правила приема мигрантов.

Представители обеих ветвей власти в Италии - и законодательной, и исполнительной пришли к единому мнению о необходимости исключить подписание Глобального догово́ра о миграции как угрожающего и без того шаткой внутренней миграционной ситуации в стране. В качестве замены Догово́ру итальянским парламентом принят закон, ужесточающий правила приёма мигрантов и беженцев, а также увеличивающий сроки содержания мигрантов под стражей для идентификации личности. Также законом предусматривается ограничение видов помощи мигрантам, прибывшим из стран с относительно благополучными демократическими режимами.

\footnotetext{
1 Italy Adopts Hardline Immigration Law. Gatestone Institute. International Policy Council. 2018. URL: https://www.gatestoneinstitute.org/13392/italy-immigration-law.

${ }_{3}^{2}$ Ibid.

${ }^{3}$ Many worldwide oppose more migration - both into and out of their countries. Pew Research Center. 2018. URL: http://www.pewresearch.org/fact-tank/2018/12/10/many-worldwide-oppose-more-migration-both-into-and-out-of-theircountries/\#more-309372.

${ }^{4}$ Italiya otkazalas podpisyvat globalnoe soglashenie po migracii. Politros. 2018. URL:https://politros.com/136215italiya-otkazalas-podpisyvat-globalnoe-soglashenie-po-migracii.
}

Научно-аналитический вестник ИЕ РАН, 2019, №2 
Такая политика нашла отклик среди большинства итальянцев, всё более склоняющихся к поддержке правых и крайне правых партий и движений, что подтверждается результатами опросов общественного мнения. Отношение к мигрантам у коренных итальянцев остаётся негативным и в целом они воспринимаются как угроза социальному укладу, традициям и культуре местного общества.

\section{Список литературы}

Авилова А.В. Италия: первая крупная победа европейских популистов. Партии и движения политической альтернативы в современной Европе. Сб. статей. Отв. ред. В.Я. Швейцер. ДИЕ РАН, № 357, М., 2018. С. 85-90.

Алексеенкова Е.С. Италия и Франция: конфликт по вопросу будущего ЕС. Научно-аналитический вестник ИЕ РАН, №1(7), 2019. М. С. 36-42.

Биссон Л.С. Миграция вновь нарушает единство Евросоюза. Европейский Союз: факты и комментарии. М., 2018. Вып. 94. С. 60-63.

ЕС перед вызовом миграционного кризиса. Позиции европейских стран. Под ред. Н.К. Арбатовой, А.М. Кокеева. М., ИМЭМО РАН, 2016. С. 29-33.

Италия в начале XXI века (сб. статей по итогам конференции). Отв. ред. А.В. Авилова, Ю.Д. Квашнин. М., ИМЭМО РАН, 2015. С. 64-72.

Маслова Е.А., Сорокова Е.Д. Россия - Италия: концептуальный анализ двусторонних отношений. Современная Европа, №1, 2019. С. 48-59.

Потемкина О.Ю. Глобальный договор о миграции - успех или провал? Научно-аналитический вестник ИЕ РАН, №6, 2018. М. С. 86-91.

\section{References}

Alekseenkova E. Italiya i Frantsia: konflikt po voprosy buduschego EU. Nauchno-analyticheskiy vestnik IE RAN, №1(7), 2019. P. 36-42.

Avilova A. Italiya: pervaya krupnaya pobeda evropeiskih populistov. Parties and Movements of Political Alternative in Contemporary Europe. Reports of the Institute of Europe, № 357. 2018. P. 85-90.

Conversione in legge, con modificazioni, del decreto-legge 4 ottobre 2018, № 113. Parlamento Italiano. 2018. URL:http://documenti.camera.it/leg18/pdl/pdf/leg.18.pdl.camera.1346_A.18PDL00 37320.pdf.

Global Compact on Refugees. URL: https://refugeesmigrants.un.org/ru/refugees-compact.

Italian monthly arrivals. Italian Ministry of Interior. Department of civil liberties and immigration. 2018. P. 1-9.

Italy Adopts Hardline Immigration Law. Gatestone Institute. International Policy Council. 2018. URL: https://www.gatestoneinstitute.org/13392/italy-immigration-law.

Italiya otkazalas podpisyvat globalnoe soglashenie po migracii. Politros. 2018. URL: https://politros.com/136215-italiya-otkazalas-podpisyvat-globalnoe-soglashenie-po-migracii.

Many worldwide oppose more migration - both into and out of their countries. Pew Research Center. 2018. URL: http://www.pewresearch.org/fact-tank/2018/12/10/many-worldwide-opposemore-migration-both-into-and-out-of-their-countries/\#more-309372.

Maslova E., Sorokina E. Rossiya - Italiya: konceptual'nyi analiz dvustoronnih otnosheniy. Sovremennaya Evropa, №1, 2019. P. 48-59.

Mixed Migration Flows in the Mediterranean. Compilation of Available Data and Information. 
International Organization for Migration (IOM). 2018. P. 13-15.

More Than 150 Nations Adopt UN Migration Pact. Voice of America. 2018. URL: https://www.voanews.com/a/un-migration-pact/4693902.html.

OECD, International Migration Outlook 2014. OECD Publishing. Paris. 2014.

TESTI ALLEGATI ALL'ORDINE DEL GIORNO della seduta № 102 di Martedì 18 dicembre 2018. Parlamento Italiano. 2018. URL: http://www.camera.it/leg18/995?sezione=documenti\& tipoDoc $=$ assemblea_allegato_odg \&idlegislatura $=18 \&$ anno $=2018 \&$ mese $=12 \&$ giorno $=18$.

\section{Why Italy opposes the Global Agreement on Migration?}

Author. Anna Shogunts, postgraduate student, Institute of Europe, Russian Academy of Science. Address: 11-3, Mokhovaya str., Moscow, Russia, 125009. E-mail: annashoghunts@ mail.ru.

Abstract. The article describes the reasons of Italy's refusal to participate in the global initiative on regulation of migration. The author analyses political and social situation in the country and their influence on the rejection of the UN Global Compact for migration. ion, Lega.

Key words: migrants, Italy, the UN Global Compact, regulation of migration, European Un-

DOI: http://dx.doi.org/10.15211/vestnikieran2201999105 